\title{
Regional Anaesthesia
}

\section{Aracnoiditis and obstructive hidrocephalia after pinal anesthesia with prilocaine}

\author{
M. J. Hernandez Cadiz1, L. Gomez Diago1, R. Dura Navarro1, A. Ripoll Vidal1, P. Vicente1, J. De Andres Ibañez1 \\ 1 Hospital General Valencia - Valencia (Spain)
}

\section{Background:}

Neuraxial anesthesia is a widely used procedure to perform a multitude of surgical interventions. Knowledge of the technique and skill is needed to reduce possible

complications. Although with little frequency, after performing the anesthesia technique, patients can present neurological deficits

\section{Case report:}

A 44-year-old man with no previous medical history, who underwent a cystoscopy to study hematuria.

A spinal anesthesia is performed: Puncture L3-L4, unique, atraumatic. Needle n 27 Whitacre. Clear CSF (cerebrospinal fluid). $40 \mathrm{mg}$ of Prilocaine are administered. Aseptic technique and without incidents. At the end of the technique, the patient reports that he has felt paresthesias in lower left member.He is sedated with propofol during the procedure.

After finishing, the patient goes to the Post-Anesthesia Recovery Unit to continue with their care and is discharged to the hospitalization room at $2 \mathrm{~h}$, after recovery from motor block, clinical stability and without presenting any incidence.

In the room, the patient reported numbness and paresthesias in both legs and anal area.

At $48 \mathrm{~h}$, he presents progressive improvement of strength in lower limbs, so he is discharged four days after the procedure.

After 11 days of the procedure, he goes to the Emergency due to the impossibility to defecate. The examination highlights: S2S4 sensory alteration, paresis of the proximal musculature of both lower limbs, subjective hypoesthesia perianal area.Lumbosacral MRI is also performed urgently, evidencing the roots of the cauda floating on a liquid discretely denser than CSF, from L2 to L5, as well as edematous appearance of the covers that enhance after the administration of contrast (Figure 1).
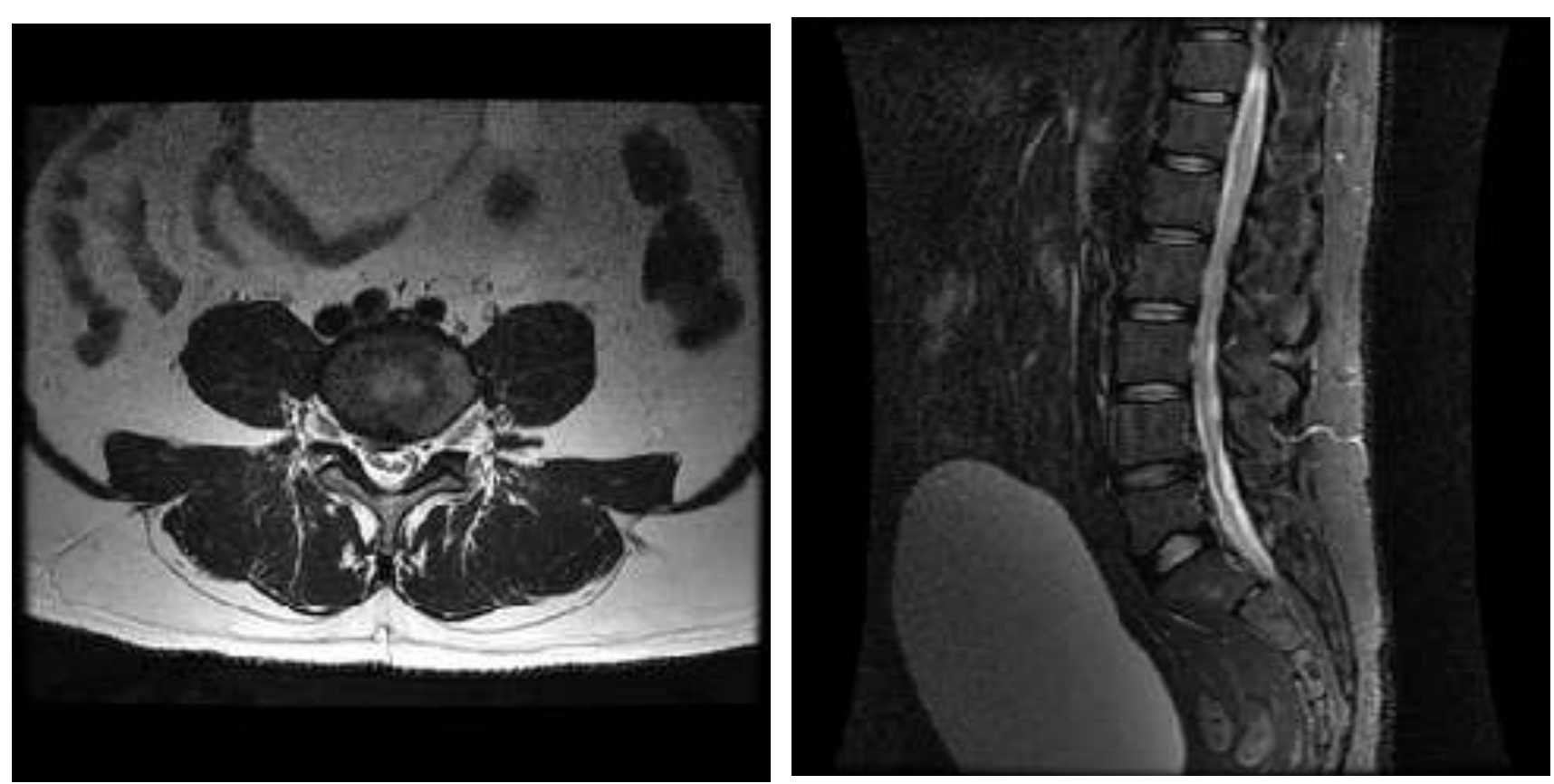

The patient is diagnosed with arachnoiditis secondary to spinal anesthesia.

Treatment with Methylprednisolone $1 \mathrm{~g}$ was decided for 5 days.

He presented progressive improvement of strength in lower limbs, sensory improvement, maintained defecation and spontaneous micturition, so he was discharged 13 days after admission.

Figure 1.

Learning points: Spinal anesthesia, prilocaine, aracnoiditis.

\section{Reference:}

1. Neal JM, Kopp SL, Pasternak JJ, Lanier WL, Rathmell JP. Anatomy and Pathophysiology of Spinal Cord Injury Associated With Regional Anesthesia and Pain Medicine: 2015 Update. Reg Anesth Pain Med. 2015 Sep-Oct;40(5):506-25.

2.Neal JM. Anatomy and pathophysiology of spinal cord injury associated with regional anesthesia and pain medicine. Reg Anesth Pain Med. 2008 SepOct;33(5):423-34

3. Chen X, Xu Z, Lin R, Liu Z. Persistent cauda equina syndrome after cesarean section under combined spinal-epidural anesthesia: a case report. J Clin 